FORMATION Formation emploi

Revue française de sciences sociales

132 | octobre-décembre 2015

Enseignement supérieur et mondes économiques : de nouveaux éclairages

\title{
Edito : Les subtiles relations entre formation et mondes économiques
}

Jean-Frédéric Vergnies

\section{OpenEdition}

Journals

Édition électronique

URL : http://journals.openedition.org/formationemploi/4529

DOI : 10.4000/formationemploi.4529

ISSN : 2107-0946

Éditeur

La Documentation française

Édition imprimée

Date de publication : 30 décembre 2015

Pagination : 1-2

ISSN : 0759-6340

Référence électronique

Jean-Frédéric Vergnies, «Edito : Les subtiles relations entre formation et mondes économiques», Formation emploi [En ligne], 132 | octobre-décembre 2015, mis en ligne le 28 janvier 2016, consulté le 30 octobre 2020. URL : http://journals.openedition.org/formationemploi/4529; DOI : https://doi.org/ 10.4000/formationemploi.4529

(c) Tous droits réservés 


\title{
Les subtiles relations entre formation et mondes économiques
}

\author{
Jean-Frédéric Vergnies \\ Rédacteur en chef
}

Dans leur introduction, Olivia Chambard et Laurène Le Cozanet nous invitent à envisager les relations entre éducation et mondes économiques, non seulement en termes d'insertion professionnelle, mais aussi autour d'enjeux variés.

Le système éducatif et l'économie sont en grande partie des univers " encastrés " ${ }^{1}$ plutôt qu'autonomes. Ce numéro propose de mieux identifier certaines voies de cet encastrement : professionnalisation, gestionnarisation, financiarisation, internationalisation... et parfois aussi leurs limites.

Il est utilement rappelé que la professionnalisation de l'enseignement supérieur est un enjeu ancien, aussi bien à l'université que dans les écoles d'ingénieurs (voir respectivement les articles de Christelle Dormoy-Rajramanan et d'Antoine Derouet). Les débats sur la professionnalisation sont ainsi bien antérieurs à la montée du libéralisme économique.

Ces dernières années, le fonctionnement même du système éducatif se "gestionnarise ". Ainsi l'administration des carrières des enseignants du supérieur s'inspire de plus en plus de la gestion des ressources humaines pratiquée dans les entreprises, comme nous le montre Simon Paye dans le cas du Royaume-Uni. Elle s’inscrit dans le déploiement du nouveau management public ${ }^{2}$ (Rouban, 2013).

1. Cf. K. Polanyi qui considère que l'économie n'est pas un domaine social autonome mais «encastré » dans la sphère sociale et politique, Polanyi K. (1983), La grande transformation. Aux origines politiques et économiques de notre temps, Paris, Gallimard, 419 p. Voir aussi Jean-Louis Laville, «Encastrement et nouvelle sociologie économique : de Granovetter à Polanyi et Mauss ", Revue Interventions économiques [En ligne], 38 | 2008, URL : http://interventionseconomiques.revues.org/245

2. Rouban L. (2013), «Postface : L’emploi public face au nouvel ordre gestionnaire », Formation Emploi, 1/2013, n ${ }^{\circ} 121$, pp. 127-137 - URL : www.cairn.info/revue-formation-emploi-2013-1-page-127.htm. 
La financiarisation de l'enseignement supérieur se développe aussi, et une partie des établissements privés sont maintenant dirigés par des groupes financiers qui investissent dans l'éducation. Aurélien Casta en dresse ici un premier panorama exploratoire.

Dans la postface de ce dossier, Hugo Harari-Kermadec et Léonard Moulin soulignent la dimension internationale de la mise en concurrence des établissements. Cela interroge le financement même de l'éducation et le montant des frais d'inscription. Là encore, le financement des études par les familles et les jeunes devient un marché. L'exemple américain révèle l'ampleur et les dérives possibles d'un tel système ${ }^{3}$.

Hors dossier, deux articles rappellent que la relation des jeunes au marché du travail et à la logique de la professionnalisation constitue un processus non-linéaire. Il reste difficile, pour certains jeunes, de construire un projet professionnel tant le monde du travail reste distancié, comme le montre Yvette Molina dans le cas des professions du travail social. De son côté, Philippe Bregeon souligne que si certains jeunes peu dotés scolairement sont " intégrés» ou " hypervolontaristes», d'autres en revanche sont " autonomes » voire " empêchés » par rapport au marché du travail.

Ainsi ce numéro illustre comment les relations entre formation et mondes économiques renvoient à des processus divers : professionnalisation, gestionnarisation, financiarisation, internationalisation et mise en concurrence, mais aussi à des processus subtils d'intégration sociale.

Bonne lecture

3. Alors que le budget du ministère de l'Enseignement supérieur était de 26 milliards d'euros en 2014, "Entre 2008 et 2012, la dette moyenne étudiante a en effet augmenté de $6 \%$ par an, et sélève aujourd'hui à 29400 dollars par étudiant ayant contracté un prêt. En 2014, environ 40 millions d'Américains ont un prêt étudiant (...) L'encours total des prêts aux étudiants (...) atteignait 1110 milliards de dollars au premier trimestre 2014", Bulletin de la Banque de France, n 197, 3 ème trimestre 2014. 